\title{
Service Quality of Urban Transportation in Indonesia
}

\author{
$1^{\text {st }}$ Dian Arlupi Utami \\ Department of Public Administration \\ Faculty of Social Sciences and Law, \\ Universitas Negeri Surabaya \\ Surabaya, Indonesia \\ dianarlupi@unesa.ac.id
}

\author{
$2^{\text {nd }}$ Supriadi Torro \\ Faculty of Social Sciences \\ Universitas Negeri Makassar \\ Makassar, Indonesia \\ supriaditorro@unm.ac.id
}

\author{
$3^{\text {rd }}$ Lexie Lumingkewas \\ Public Administration Department \\ Faculty of Social Sciences \\ Universitas Negeri Manado \\ Manado. Indonesia \\ lexielumingkewas@unima.ac.id
}

\begin{abstract}
The Department needs to implement public policy guidelines to increase the competitiveness of the city and reduce the impact of growth. Many businesses are important to point out the people's performance on their journey. These are the main reasons for this service with good reasons for caring for the community, problems in the cities. Promote the importance of managing the public and integrating good causes and evaluating the city's diversity, public awareness, and the impact of the city. Expand research on the nature of education that is relevant to public interest. Decides to increase the quality of service available to the customer.
\end{abstract}

Keywords: service quality, urban transportation, public transportation

\section{INTRODUCTION}

The industry plays associate more and more vital role within the economy of the many countries like as land. This movement from one place to a different through conveyance from a part of the day to day activities of most people within the developed and developing countries. Conveyance refers to the means that by that larger proportions of urban dwellers gain physical access to the products, service, and activities they have for his or her livelihoods and well being [1]. Public transportation plays an important role in travelling to activities areas like work, school, shops, sporting and recreation centers [2]. Public transportation includes all transport facilities within which passengers don't use their personal means that of transportation to travel [3]. This includes taxis, minibus, buses, and trains. In Ismail opinion's that public transportation performs several functions like providing quick access, safe, economical and price effective transport services to passengers [3]. Besides, the straightforward of use (availability) and price effectiveness of conveyance service is imperative to guaranteeing a resilient economy and up quality. Societies conjointly edges from the availability of public transportation services such it lessens traffic congestion on our roads, saves cash and creates and sustain jobs at intervals communities [3].

Travelling publicly transport with high level of facilities, convenience and quality is vital for traveler satisfaction [4]. Customer desires and expectations are dynamic once it involves governmental service and their quality necessities. However, Teicher, et al. explains that service quality practices publicly sector organizations is slow and is more exacerbated by difficulties in activity outcomes, larger scrutiny from the general public and press, an absence of freedom to act in associate arbitary fashion and a demand for selections to be based mostly in law [5]

\section{RESEARCH METHODS}

The type of this analysis is descriptive analysis with qualitative approach that is outlined as a shot to present a descriptive description or describe a collectivity with the condition that the representatives are warranted. the main focus of this analysis is service quality publicly sector, quality factors publicly transport, condition public transportation in land, public transportation development, transportation challenge in urban areas, some public transportation project in massive cities in Indonesia.

\section{RESULT AND DISCUSSION}

\section{A. Service Quality in The Public Service}

Public sector services are responsibility and responsible to voters and communities in addition on its customers. Many researchers have restrained service quality publicly service declared that the literature clearly supported the employment of comparison methodology in analyzing the information between personal and public sector operators [6]. Service provision is additional advanced within the public sector as a result of it's not merely a matter of meeting expressed desires [7] however of looking for unvoiced desires, setting priorities, allocating resource. The need for folks to fulfill social and economic desires typically end in increasing transport demand [8]. It's evident that man has been concerned within the transportation of foods, materials, info and alternative service from prehistoric times. In a very developing tie up, pollution and country wherever folks are additional obsessed with the car, the rates of tie up, pollution, and accident are high. Analysis has unconcealed that, the demand for conveyance relies on 2 major factors: (i) the will to form a specific stopover at all and therefore the drive to try and do thus by conveyance, and (ii) probably the characteristics and nature of public 
transportation modes that are accessible. Formal conveyance system is high traveler occupancy vehicles, which are typically provided by government and alternative government and non-governmental agencies at users' prices within the type of fares. Formal conveyance system is deemed important as a result of the subsequent reasons; (i) the expansion of personal automobile use tends to accentuate congestion value, surroundings hazards, energy value, that are socially and politically unacceptable. However, in less developed countries, the provision of conveyance is much below the demand for the mode. What is more the general public transport system are grossly mismanaged and in most case inefficient. The relative short fall of the traditional conveyance in several countries autoimmune disease to be thought of a completely unique innovative mode of operation currently called unconventional or para-transit because the case could also be. This has been the case in places wherever conveyance equipped is lean to fulfill the travel want of the population. Consequently several of the vehicles used as informal conveyance are creaking, smoky, and wobbly.

The urban population, embedded in grouping typically faraway from food and stuff sources, jobs and leisure, has to move in a very advanced conveyance system. The regime acts fixing the price ticket worth, maintaining lines and frequency that aren't even economically [9]. Public bus companies are the foremost widespread, cheap and wide provided conveyance modes in several urban and rural areas of the many countries. A superb public bus company is vital to support the economic process, the growing population and therefore the growth of urban or rural activities [10]. A public bus company ought to give a decent access-ability that ends up in reliable, safe, intelligence, convenience and effectives of facility. Except that, associate economical public bus company enhances personal economic opportunities, saves cash and reduces the environmental impacts. In reality, however, if the standard of services is poor and unreliable, the general public bus services tend to contribute to the worsening of the facility. There are variety of problems concerning public bus services like the limitation of facilities, the employment of inferiority of public facilities and interchanges, inconvenience fleet, dispatching low traveler journeys and long waiting time [11][12].

Geographical factors like population, environment, economic and culture are among the factors that influence the bus operation service provided. The kind and options of urban bus company might disagree from rural bus services wherever coverage routes, fare system and fleet rely upon the native desires. Commonly, in several urban and country, public facility deals for the most part with problems and issues encountered with transportation services, operation, infrastructure and facilities [13]. Contrary to urban areas, public bus system in rural areas, as an example is nice and additional functioning as mode helping in reducing automobile dependency to preserve the geo-culture and sustaining the region. Determinate of service level rural areas aren't driven by factors like financial gain level and journeys pattern compared to those of urban areas, as a result of services in rurally are additional of social obligation in nature. Though an in depth approach of transformation programs in urban public bus services is extremely abundant required, matters could also be totally different for rural areas, with tiny population and various activity locations.

\section{B. Quality factors in public transport}

The key issue in analyzing the standard factors publicly transport is to find the important parts of perceived quality and their relative coefficient above all. A world literature survey was undertaken 1st so as to get a full image of the component of perceived total quality. According Friman [14], below are a number of the conclusions and observations made up of international studies and therefore the discussions held:

- The perceived total quality of public transportation is that the results of the combined impact of objective (actual period, actual travel value, accidents, if any, etc.) and subjective factors in individual travel experiences accumulated over extended amount of your time.

- Satisfied passengers understand conjointly the standard of the general public transport service they receive nearly as good.

- Traditional measurable quality and traveler satisfaction part disagree from each other,Passengers might feel overall conveyance quality has deteriorated notwithstanding observation of the operator's quality criteria indicates it's remained unchanged or has even improved.

- Quality factors that are looked as if it would be so as and to that very little attention is thus paid in daily travel things will simply be undervalued.

- Quality factors that are perceived as requiring abundant improvement are deemed to be vital notwithstanding objectively speaking, they're of minor importance in terms of overall conveyance service.

- Awareness of quality improvement in a very given sector might increase expectations conjointly with relevancy alternative factors impacting on perceived total quality.

- Negative feedback is given additional pronto on parts with shortcomings.

- Punctuality of service encompasses a terribly high impact on traveler satisfaction and passengers' perception of conveyance quality.

- Travel time is a superb example of a subjectively perceived quality factors [15], if there are many stops finish route, total period is perceived as shorter if the stops return at irregular intervals, the additional interruptions and disruptions on the method, the longer the travel is looked as if it would take despite actual period being precisely the same as in uninterrupted circumstances. 


\section{Conditions of public transportation in Indonesia}

Besides the poor conditions and growth of road infrastructure, the state of Indonesian public transportation services, principally bus systems, therefore presents an adverse development. The extraordinarily high growth rates of motorbikes have additionally created some difficulties in managing traffic thanks to driver behavior. However, will increase in motorcycle use are inevitable; the mode has become a "way out" for a few travelers thanks to poor road infrastructure and public transportation services. The rising trend of motorcycle use among travelers isn't happening solely in urban or town journeys however additionally in intercity journeys and long-distance journeys. The chief reasons that individuals pick motorbikes as their transportation mode of selection are the mode's simple possession and economical operations. Motorbikes are low cost and simple to get through an easy credit method. Motorcycle operations and maintenance are economical and reasonable for several individuals in numerous financial gain layers. The dramatic increase within the use of motorbikes has given rise to traffic accidents and casualties, as well. As AN extreme illustration, Djakarta remains experiencing the huge growth of motorcycle use; the amount of motorbikes will increase by quite one thousand units per day, whereas its automobile counterparts return to concerning three hundred units per day. The negative impact of motorbikes on traffic accidents contributes to concerning 2-3 casualties per day. To mitigate traffic accidents, that price not solely human lives however additionally economic prosperity, one thing has to be done to scale back the utilization of motorbikes. Combating the utilization of motorbikes is, however, not easy. Additionally to being straightforward and low cost to have and economical to use, motorbikes are thought-about a good mode of transportation on full roads. Motorcycle riders will save on period of time and even create multiple journeys on a daily basis, giving them luxuries that alternative modes don't supply. Some surveys have additionally according that motor-bikers ar saving a good deal on travel prices as a result of their expenses ar a lot of but those of public transportation riders - even the most cost effective kind of public transportation, the bus [16].

\section{Public transportation development}

Countermeasures aimed toward reducing traffic accidents from the "human factor" viewpoint are enforced for quite it slow through traffic enforcement, strict controls on the supply of driving licenses, and robust penalties for traffic violators, however these initiatives are insufficient; there's still important space for improvement within the context of non-human factors like infrastructure and alternative suggests that of transportation. up public transportation and infrastructure before any modal decisions by travelers is crucial, as doing therefore would facilitate travelers create rational decisions intended not just by the straightforward want to flee somehow from the staggeringly poor conditions of the present transportation provides. Motorcycle use has become the incorrect selection for the full transportation. Motorcycle behavior has created substantial holdup and violations, leading to several traffic incidents and accidents. Since 2004, Jakarta, as an example, has enforced "three pillars" of urban transportation solutions: rushing up road infrastructure development, increase additional public transportation modes, and implementing additional traffic management measures. Summarizes the 3 pillars of solutions. The expansion of travel demand in country forever outstrips offer thanks to comparatively high and stable economic process. Road infrastructure grows slowly relative to the expansion of road-based motorized transportation modes. Motorbikes became a preferred selection for transportation not solely in massive cities like Djakarta however additionally in several alternative cities within the country. Reducing the amount of journeys created by motorbikes, then, is one in every of the ways in which to enhance the general transportation and mitigate the adverse impact of motorbikes on traffic accidents [16].

\section{E. Transportation challenges in urban areas Public}

Public transportation, and transportation generally, may be a difficult endeavor in urban areas. As bound town populations grow, and as their economic bases shift and evolve and their housing sector adjusts, even additional vehicles are coming into the roads daily. One of the effective answer to decreasing the pressure on town streets and highways is maintaining a strong public transportation, however trendy urban areas bring a number of challenges to the table for transit agencies, a number of which might be alleviated by correct and forward-thinking transit management, and alternative which can ought to return from the municipal level on down. Here are 5 major challenges for transit in urban areas [13] [9]:

1) Traffic congestion: The sheer variety of vehicles on town roads daily simply carrying one person on their daily commute to figure is big, and once else to the delivery trucks and vans, service vehicles, and buses and taxis out there driving daily, will cause huge snarl-up. It contributes to rising tensions, additional fuel use, higher amounts of pollution, and slower commutation times, whereas additionally serving up the foremost challenge of finding an area to park most of these vehicles close to their destinations. Delivery vehicles and buses might not contribute to the deficit in parking places, however they will be a supply challenge for alternative drivers to navigate around throughout their route stops.

2) Long commutes: raised traffic, road construction, and a population that progressively lives in one a part of town and works in another all contribute to longer commute times. Cities will address the difficulty through an evolution of their coming up with work to include various transportation modes (such as biking and walking), supporting additional walkable neighborhoods, and therefore the higher promotion and promoting of transit choices as additional productive various to driving. Transit agencies will work to make system that are simply passable, with additional opportunities for multi modal transportation connections, which are designed to urge smarter over time.

3) Secondary infrastructure: to boot, allowances ought to be created for additional bike and scooter parking at routes, still as raised access to bike racks on the transit vehicles themselves. 
4) Sprawling cities: As several cities grow progressively outward, urban and residential area sprawl places each residential and business realty more faraway from the centre, and this decentralization results in not solely progressively advanced transit and road system, however additionally to long commutes and drive time traffic woes. Transit agencies will work toward smarter long routes that would embrace additional direct routing with fewer stops throughout bound hour, or extra shorter routes with additional frequent stops throughout others, and will work on a comprehensive set of choices for its riders that has multiple modes of transportation to hurry commutes.

5) Large fleets, massive cost: Transits agencies in geographical area, that manage larger fleets of vehicles and additional staff, have their challenges cut out for them in terms of keeping maintenance price and tasks in check, still as attracting, training, and retentive a talented work force, that contributes to raised safety and fewer lost-time accidents. The adoption of technology systems for higher route programing, maintenance trailing, and worker programing will facilitate scale back price and period of time, as will the implementation of higher trailing, mapping, and communications systems on the vehicles themselves. Cities will facilitate change additional economical transit systems by partnering with agencies in planning processes, the sharing of resources, and following forward-thinking answer like electrical buses.

Public transportation may be a terribly effective answer to a number of the quality problems in cities and concrete areas, and though it additionally comes with a collection of challenges, transit agencies and town governments will take steps toward faster and additional price effective systems for obtaining individuals wherever they have to travel once they ought to go there.

\section{F. Some public transportation projects in big cities in Indonesia}

Bus Rapid Transit (BRT) in Jakarta has in all probability been the foremost aggressive public transportation development project in Indonesia since 2004. The system already has 12 (twelve) of the 15 (fifteen) corridors stipulated within the set up, with the present corridors covering 208 kilometer in total length and carrying quite 300,000 passengers on a daily basis. The three new corridors are currently beneath construction and being developed as elevated infrastructure, and therefore the Djakarta government has created it a policy to extend the amount of vehicles within the service fleet. Not solely BRT however additionally non-BRT bus systems are currently being revitalized in terms of their network structures, vehicles, and management.

The $1^{\text {st }}$ Mass Rapid Transit (MRT) project in Jakartathe first of its kind within the country-is additionally beneath construction for the north-south passageway and being supported by national and sub-national governments through a soft loan from the Japanese government. As overseas loans ought to bear national governments, the Indonesian government is extending the money theme to the sub-national Jakarta government through granting and loaning loans. The primary section of the MRT north-south passageway is concerning fifteen kilometer (Lebak Bulus-
Bundaran HI) long and can be extended up to Kampung Bandan (the northern a part of Jakarta). The east-west MRT passageway, currently in preparation for elaborated engineering style, can serve not solely Djakarta however additionally 2 alternative provinces (West Java Province and Banten Province).

The most recent public transportation project in Djakarta, an attempt being followed additionally by Palembang town in South Sumatera, is lightweight public transit (LRT). LRT technology has additional sensible benefits than MRT offers, principally in terms of land acquisition. The LRT being projected and designed uses the airspace and air rights of the present road network and, thanks to its sensible mobility, permits horizontal and vertical alignments. Djakarta town features a basic 7corridor LRT style at intervals the city; 2 of the corridors are given development priority in an attempt to confirm sleek transportation service throughout the future Asian Games event in 2018. an analogous set up has additionally been introduced in Palembang South Sumatera, as Palembang are going to be a supporting host town for the Asian Games. Another LRT project presently afoot involves establishing 2 LRT corridors to serve inter-city passengers in Jabodetabek (Jakarta, Bogor, Depok, Tangerang, and Bekasi, or the "greater Jakarta" area). All the LRT comes are mistreatment national and sub-national budget funding for infrastructure and personal, semi-private, or state-owned company budgets for the specified rolling stocks and systems. The participation of non-governmental bodies within the initiative can doubtless accelerate public transportation development within the country and enhance accessibility and quality for alternative non-public development comes like properties.

\section{CONCLUSION}

Public transport refers to the means by which larger proportions of urban dwellers gain physical access to the goods, service, and activities they need for their livelihoods and well being. Public transportation is a very effective solution to some of the mobility issues in cities and urban areas, and although it also comes with a set of challenges, transit agencies and city governments can take steps toward

\section{ACKNOWLEDGMENTS}

The author would like to be thankful to Surabaya State of University and Social Science and Law Faculty for this manuscript.

\section{REFERENCES}

[1] G. Fiitzgerald, "The Social Impact of poor access to transport in rural New Zaeland," New Zealand, 2012.

[2] R. Kamaruddin, I. Osman, and C. A. C. Pei, "Public transport services in Klang Valley: Customer expectations and its relationship using SEM," Procedia-Social Behav. Sci., vol. 36, pp. 431-438, 2012.

[3] T. K. Ojo, D. O. Mireku, S. Dauda, and R. Y. Nutsogbodo, "Service Quality and Customer Satisfaction of Public Transport on Cape Coast-Accra Route, Ghana," Dev. Ctry. Stud., vol. 4, no. 18, pp. 142-149, 2014. 
[4] C. A. Wojuade and A. I. Badiora, "Users' Satisfaction with Public Transport Operations in Ibadan, Nigeria," J. Soc. Sci. Res., vol. 3, no. 9, pp. 88-96, 2017.

[5] R. P. Munhurrun, L. D. S. Bhiwajee, and P. Naido, "Service quality in the public service," Manag. Mark. Res., vol. 4, no. 1, pp. 37-47, 2010.

[6] R. Ismail, M. . Hafezi, and R. M. Nor, "Passenger preference and satisfaction of public transport in Malaysia, Part II: A comparative analysis of Komuter and LRT network," Reseaarch J. Appl. Sci. Enggineering Technol., vol. 6, no. 8, pp. 1450-1456, 2013.

[7] M. C. Vijayakanth Urs, A. N. Harirao, and A. N. S. Kumar, "Customer Satisfaction through Service Quality in Public Service (Volvo Buses) Compared with Private and Government Operators Accross Kartanaka," Int. Juornal Emerg. Res. Manag. Technol., vol. 3, no. 5, pp. 87-99, 2014.

[8] O. Fadare and B. T. Salami, "Telephone uses and the travel behaviour or residents in Osogbo, Nigeria: an empirical analysis," J.Transp.Geogr, vol. 12, pp. 159164, 2004.

[9] V. Pina and L. Torres, "Analysis of the efficiency of the local government service delivery. An application to urban public transport, Transportation Research Part A," vol. 35, pp. 929-934, 2001.

[10]S. Bachok, M. M. Osman, and Z. Ponrahono, "Passenger's aspiration towards sustainable public transportation system: Kerian District, Perak, Malaysia," Procedia-Social Behav. Sci., vol. 153, pp. 553-565, 2014.

[11]M. M. Rohani, D. C. Wijeyesekera, and A. T. A. Karim, "Bus operation, quality service and the role of bus provider and driver," Procedia Eng., vol. 53, pp. 167-178, 2013.

[12]Z. Ponrahono, S. Bachok, M. Ibrahim, and M. M. Osman, "Assessing passenger's Satifaction level on Bus services in selected urban and rural centres of penisular Malaysia," Procedia-Social Behav. Sci., vol. 222, pp. 837-844, 2016.

[13]R. N. R. Arifin and R. K. Zahari, "Toward a sustainable urban transport system in the Klang Valley, Malaysia: The key challenges," Procedia-Social Behav. Sci., vol. 85, pp. 638-645, 2013.

[14] M. Firman, "Implementation Quality Improvements in Public Transport," J. Public Transp., vol. 7, no. 4, 2004.

[15] Y. Li, "Evaluating the urban commute experience: A time Perception approach," J. Public Transp., vol. 6, no. 4, 2003.

[16] S. Soehodho, "Public transportation development and traffic accident prevention in Indonesia," IATSS Res., vol. 40, no. 2, pp. 76-80, 2017. 